\title{
Policy Stringency under the European Union Emission Trading System and its Impact on Technological Change in the Energy Sector
}

\author{
Germà Bel* \& Stephan Joseph \\ (Universitat de Barcelona \& GiM-IREA)
}

\section{(Forthcoming in Energy Policy)}

** Corresponding author: Germà Bel. gbel@ub.edu . Dep. Of Econometrics, Statistics and Applied Economics, Universitat de Barcelona. John Keynes 1-11, 08034 Barcelona, Spain. Tel: $+34934021946$

\begin{abstract}
In this study, we use patent count data for overall Climate Change Mitigation Technologies, and for those related to energy production and distribution to evaluate the relationship between the sizable oversupply of European Union emissions Allowances and a policy shift marked by the transition from Phase I to Phase II under the European Union Emission Trading System, on the one hand, and on "green" patenting, on the other. According to our results, the expected negative impact of this oversupply on technological change seems to be confirmed. Thus, stakeholders take the actual supply of certificates into account when determining their innovative activity. In the same vein, they do so with respect to policy changes related to greater stringency, which generated a sizeable increase in patenting activity when controlling for other economic factors. Our results suggest that a critical evaluation of emission caps and allowances distribution must be undertaken.
\end{abstract}

Key words: Environmental Policy; Emission Trading System; Policy Stringency; Technological Change; Patent Count Data; Energy Sector

JEL Codes: Q55; Q58; O33; O38 


\section{Policy Stringency under the European Union Emission Trading System and its Impact on Technological Change in the Energy Sector}

\section{Introduction}

Technological change aimed at mitigating the impact of economic activity on climate change is a powerful tool for moving towards a low-carbon economy. To strike out on this path, various policies have been adopted worldwide. One of these is the European Union Emission Trading System (EU ETS) which, as a market-based regulation, established the first and largest market for greenhouse gas (GHG) emissions allowing installations in the system to cut their emissions in a flexible and cost-efficient way. However, external shocks and a lack of stringency have led to the creation of a sizeable oversupply of allowances in the market, potentially hampering the effect of the policy on low-carbon technological change (Sandbag 2013).

Against this backdrop, the first goal of our study is to determine empirically whether this oversupply of allowances in the market has a negative effect on the outcome of the creative process in countries covered by the policy. Secondly, we examine how policy changes introducing greater stringency affect innovative behavior ${ }^{1}$. To this end, we use a count data model to estimate the impact of certificate oversupply on climate change mitigation technologies (CCMTs) in the energy sector. We focus on this sector because it is the most productive in terms of CCMT patenting, and we provide information on the selection of this patent variable in Table A-1 (and include details explaining the Y02 class). Furthermore, because a policy shift occurred in 2008, we use a binary variable (described in section IV) to evaluate the impact of this shift, which is arguably an additional effect to that of increased stringency, for the period 2008-2012.

With this study we seek to contribute to the literature by analyzing how innovation responds, on the one hand, to lax policies and, on the other, to more stringent guidelines. We take

\footnotetext{
${ }^{1}$ Performance evaluations of public policies previously implemented can help improve and modify existing policies (Guimarães et al. 2010).
} 
the specific case of the EU ETS and measure stringency in terms of the number of excess permits in the market. We expect a less stringent EU ETS to result in a large oversupply of permits, whereas measures that increase the stringency of the trading system are expected to reduce this oversupply. As stated above, we focus our attention on technologies that seek to reduce the GHG emissions related to energy generation, transmission and distribution. To the best of our knowledge, this is the first multivariate empirical analysis to fully consider the first two phases of this policy (20052007 and 2008-2012). As such, this study specifically fills the gap in the literature examining the EU ETS and more broadly the gap in the literature concerned with any cap-and-trade regulation. Finally, we hope to broaden understanding of the way in which policy failures influence innovative behavior in the framework of such policies.

We organize the rest of the study as follows. First, we provide a brief outline of the EU ETS and its different phases and we review the literature. In section 3, we describe the structure of the data and the variables used in the empirical exercise. Next, we present the methodology and the regression outcomes, the implications of which are then discussed in relation to the research questions posed. Finally, we draw our main conclusions and highlight policy measures that might put the EU ETS on the right track.

\section{Description \& Aims of the Policy}

In 2005 the EU ETS came into operation. The trading system can be considered the European Commission's (EC) main policy for reaching its ambitious GHG reduction targets under the 2030 framework for climate and energy policies. To date, the 28 EU Member States, as well as three additional member states of the European Economic Area (EEA: Iceland, Liechtenstein, and Norway) have joined the system, making it the world's largest carbon market. The main principle of the EU ETS can be summed up quite simply as "cap and trade". The first step in the system "cap" - sees the EC set an EU-wide ceiling for GHG emissions under the policy, which is gradually reduced every monitoring period. The GHG ceiling is fixed in such a way that the EC issues socalled EU emission allowances (EUAs). These represent the right of a holder of such a certificate 
to emit one ton of $\mathrm{CO}_{2}$, or an equivalent amount of GHG with respect to its climate impact, as listed in Annex II of the EC Directive 2003/87/EC (European Commission 2013).

Hence, to reduce the EU ETS cap the EC cuts the overall number of EUAs in the market. Firms subject to this policy must cover their emissions by allowances; otherwise, they face heavy fines for every ton of $\mathrm{CO}_{2}$ emission not covered. The second step - "trade", on the other hand, permits firms in the case of a shortage of allowances to purchase additional EUAs in a common market and, so, avoid penalization for non-compliance. ${ }^{2}$ The principle underpinning the EU ETS is market-based regulation that aims to leave the means of compliance in the hands of the firms.

Currently, 11,500 installations are subject to the policy (Schmalensee and Stavins, 2017), accounting for around $45 \%$ of total GHG emissions in the participating countries. The policy only covers heavy-emitting sectors; ${ }^{3}$ this includes many manufacturing industries ${ }^{4}$ and the power generation sector. The latter is responsible for the lion's share of GHG emissions, accounting for 29\% of total GHG emission from the EU 27 (European Environmental Agency, 2014).

The EU ETS has been implemented in three phases, each marked by fundamental changes in policy design. The first phase (2005-07) can be considered a trial phase adhering to a "learning by doing" credo. Given that prior to 2005 no reliable emission data for the sectors in the new system were available, the main task was to build an EU-wide data base for GHG emissions for the participating members. Precisely due to this lack of emission data, the first phase was marked by a certificate oversupply that led to EUAs being priced at zero from mid-2006 on. ${ }^{5}$ The default distribution method for the EUAs was that of free allocation in accordance with the national allocation plans. With the second phase (2008-12), the EC sought to improve the EU ETS by

\footnotetext{
${ }^{2}$ Furthermore, EU ETS companies can cover some of their emissions using international offsets ("Kyotooffsets" - KO), stemming from Clean Development Mechanism or Joint Implementation projects.

${ }^{3}$ From 2012 on, aviation has also been covered by the EU ETS, so that all the participating countries' flights (within, outgoing, and incoming) are subject to the policy.

${ }^{4}$ Manufacturing sectors covered by the EU ETS are oil refineries, steel works and producers of iron, aluminum, metals, cements, lime, glass, ceramics, pulps, cardboards, acids, and bulk organic chemicals.

${ }^{5}$ Nonetheless, Ellerman and Buchner (2008) found a significant impact of the EU ETS first phase on CO2 emission abatement.
} 
cutting total allowances by around 6.5\% compared to the 2005 level. To counter further price corrosion, the EUAs from the first phase were not bankable into the second period, while several participants started to auction off some of their allowances as opposed to just giving them away. These actions served to strengthen the policy in its aim to cut further GHG emissions.

However, the start of the second trading period coincided with the onset of the global economic crisis (2008/09) which had a marked impact on production levels and, hence, on GHG emissions in the participating countries. For this motive, installations in the system reduced their emissions by a sizeable volume because of the economic recession, rather than their abatement efforts (Bel and Joseph 2015). This in turn led to a build-up of a considerable oversupply of allowances in the market, a problem that was exacerbated by the fact that during this second trading phase firms could cover part of their emissions by Kyoto-offsets (KOs). ${ }^{6}$ Overall, the stringency of the policy was greatly compromised.

The EU ETS is currently in its third phase (2013-2020). A major change with respect to the earlier phases is the introduction of a cap that is reduced each year by $1.74 \%$ in an attempt at reaching the emission abatement target of $21 \%$ of the 2005 level by 2020 . Likewise, the default method for allocating allowances has gradually shifted from a free-of-charge distribution to that of auctioning. The EC has also implemented the "back-loading" of additional allowances, thus postponing the auctioning of 900 million EUAs until 2019-2020. This resulted in a reduction of 400 million allowances in 2014, 300 million in 2015, and 200 million in 2016 (European Commission, 2014).

\footnotetext{
${ }^{6}$ See, for instance, Gronwald and Hintermann (2016); Hintermann, Peterson and Rickels (2016, p. 118).

${ }^{7}$ Given that the main principle underpinning the EU ETS is that of 'cap and trade' and the capping is achieved through the allocation of emission allowances, the overall number of allowances on the market determines the degree of stringency of the policy. Brunel and Levinson (2016) review various methods for measuring stringency measures, and Sauter (2014) analyzes methods for measuring environmental policy stringency. More specifically, Koźluk (2014) discusses environmental policy instruments as a measure of policy stringency.
} 


\section{Induced technological change and the EU ETS}

The main drivers of emission abatement under the EU ETS were, and continue to be, fuel switching and the impact of the global recession that hit the EU in 2008/09. Fuel switching has proved to be a valid tool for cutting emissions in a cost-efficient manner, especially in the power generation sector (Delarue et al. 2008). But, as Calel \& Dechezleprêtre (2016) point out, fuel switching alone cannot provide sufficient emission abatement to meet the ambitious EU target of an $80-95 \%$ reduction in 1990 GHG emission levels by 2050. For this reason, the EC emphasizes "the Emissions Trading System is the principal driver of the deployment of new technology, by putting a price on carbon emissions, and so stimulating the development of technologies which avoid them" (European Commission, 2015). The idea underpinning this statement is the hypothesis known as "induced innovation", which was first proposed by Hicks (1930) and later reformulated in terms of environmental regulation by Porter (1991) and Porter \& van der Linde (1995), where it is known as the Porter hypothesis (PH). One version of this hypothesis states that well-designed environmental policies can foster "green" innovations. ${ }^{8}$

3.1 Market-based regulations and its innovation impact

Many papers since then have sought to validate, both empirically and theoretically, whether environmental regulation de facto spurs environmental innovation. ${ }^{9}$ Few, however, focused on market-based regulations such as the EU ETS. Popp (2003) analyzed the innovation impact of a market-based regulation compared to that of a command-and-control regime. Contrary to theoretical predictions, the overall number of innovations as measured by patent counts did not rise after the introduction of the 1990 Clean Air Act (CAA) in the USA. On the other hand, he

\footnotetext{
${ }^{8}$ This is typically referred to as the "weak" version of the PH. The remaining versions identified by Jaffe \& Palmer (1997) are the "narrow" and the "strong" version of the PH.

${ }^{9}$ As our paper uses an empirical approach and focuses on the EU ETS, a market-based regulation, only papers analyzing such policies empirically are presented here. A more detailed overview of current literature in the field, however, can be found in Ambec et al. (2013). In addition, it is worth noting recent interesting developments in the study of factors that trigger innovation in the energy sector, which report a significant positive effect of path dependency, particularly for renewable energy technologies (see Rexhäuser and Löschel, 2015).
} 
found that the direction of technological change was altered by the policy. Although the overall number of patents decreased during the observation period, the quality of patents with respect to environmental-friendliness increased. Accordingly, the shift to a market-based regulation spurred "green" innovation.

A second paper that analyzes if "induced innovation" takes place under environmental regulation is Lanoie et al. (2011). Using data from a survey conducted in seven OECD countries, the authors empirically tested different versions of the $\mathrm{PH}$, and found strong evidence supporting the "weak" version. This finding is consistent with the fact that environmental policies alter the costs of pollution, by making them part of the production chain. Interestingly, Lanoie et al. (2011) also found some support for the "narrow" version of the PH, meaning that more flexible/marketbased regulations can potentially outperform inflexible, classical command-and-control policy regimes.

Johnstone et al. (2010) provide additional evidence that environmental policies spur innovation. Using patent counts for renewable energy sources in 25 countries for the period 19782003, the authors demonstrated that different environmental policy regimes result in innovations being made in different directions. For example, market-based regulations promote technological innovations for renewable energy sources that are in competition with fossil fuels and which are less costly to develop (e.g., wind power as opposed to solar power). As this brief review of the current literature examining the link between market-based environmental regulations and "induced innovation" shows, innovation does occur under such policy regimes and, hence, they constitute valid tools for putting an economy on a less-polluting technological pathway.

\subsection{The EU ETS and its impact on innovation}

In the case of the impact of the EU ETS, the results are far from clear, however. Although various studies aimed at untangling the impact of the trading system on innovation have been conducted, 
results remain inconclusive. Anderson et al. (2011), for instance, report a moderate stimulating effect of the policy on technological change. Following a survey conducted among EU ETS firms in Ireland, the authors conclude that nearly half the companies were engaged in the acquisition of new machinery and equipment and two thirds had performed process or behavioral changes. Likewise, Fontini and Pavan (2014) find a positive link. In an analysis of the Italian pulp and paper industry, they show a positive relation between the initiation of the second trading period and technological change in the sector. However, the reduction in emissions detected during the study period was due mainly to an overall reduction in output and not to technological change, and so they conclude that the ETS has had only a limited, albeit positive, impact on low-carbon technological change.

Similar impacts of the EU ETS were reported by Rogge and Hoffmann (2010) in an interviewbased study of the German electricity sector. ${ }^{10}$ The policy was seen to have had an impact on R\&D for carbon capture technologies, especially on large-scale, coal-based power generation; however, the authors claim that the impact was limited by the free allocation of EUAs in the market. Further evidence of the positive impact on innovation can be found in Petsonk and Cozijnsen (2007) and Martin et al. (2011), the second of these studies suggesting that the amount of freely allocated allowances hampers innovation incentives under the policy regime.

In contrast, a large number of studies attest to the fact the system has no or little influence on firms' innovative behavior. For example, Borghesi et al. (2012) show that the EU ETS has resulted in few environmental innovations among Italian manufacturing firms and attribute this to the lack of policy stability. Aghion et al. (2009) share this opinion, arguing that in a cap-and-trade system a sufficiently high carbon price is needed to induce technological change and policy stability

\footnotetext{
${ }^{10}$ Similar studies by Hoffmann (2007) and Rogge et al. (2011) come to similar conclusions but are more critical of the incentives for innovations under the EU ETS, due to the lack of stringency.
} 
is essential. However, they show that neither factor was observed during the first few years of the policy, thus hampering the development of "green" innovations.

One of the most ambitious studies, in terms of the number of firms in the system to be examined, is Calel and Dechezleprêtre (2016). To verify the true impact of the EU ETS on patenting behavior, firms in the system were matched with other firms of similar characteristics and a difference-in-difference estimation was performed. This showed that the EU ETS was responsible for just a $2 \%$ increase in low-carbon patenting and that the impact of the policy on "green" technological change has been limited to date.

Likewise, Martin et al. (2012) performed an evidence review of existing literature examining various features of the EU ETS, including emission abatement, economic performance and also innovation. In the case of the latter, the study could find no strong evidence that the EU ETS is driving technological change for directly regulated firms.

In the following sections, we conduct our empirical exercise, which allows us to make several contributions to the literature. First, we show how stringency under EU ETS, expressed in terms of oversupply, on the one hand, and policy regime changes, on the other, affects innovative behavior in those countries subject to the EU ETS. We are thus able to give an initial percentage estimate of these two effects under the EU ETS. Second, we separate the impact of oversupply and policy changes with respect to overall CCMTs and technologies for the reduction of GHG related to energy generation, transmission and distribution. Finally, we should stress that, while the papers listed above only cover the first phase of the EU ETS, our study deals with the second phase as well.

\section{Data Sources and Variables}

In order to account properly for the cross-national character of the EU ETS, we constructed a longitudinal data set covering the 27 states of the EU plus the EFTA-state Norway between 2005 and 2012, thus taking the first two trading periods into account. We begin our analysis in 2005 
because in 2004, 10 states accessed the EU (followed by a further two in 2007). Data prior to accession lack the necessary homogeneity and completeness that our analysis demands. We choose 2012 as the final year for our study because the second EU-ETS phase terminated that year. As such, we can evaluate two complete phases.

Our final data sample comprises 217 observations. ${ }^{11}$ Data for this study have been taken from Eurostat, with the exception of the variables related to the EU ETS (i.e. allocated allowances and verified emissions), which were provided by the Community Independent Transaction Log (CITL).

\subsection{The dependent variables: Patent Counts for CCMT}

To measure the innovative activity of countries covered by the policy, we use patent counts of CCMTs as a proxy, in line with earlier studies, e.g. Calel and Dechezleprêtre (2016). The advantages and disadvantages of using patents as an output measure of the creative process have been widely discussed. The typical drawback of patent data is that they only capture part of the outcome of innovative activities, since not all technological improvements are patented, voluntarily or otherwise, while innovations might also be of an organizational nature [Popp (2003, pp. 658-659); Mazzanti and Zoboli (2006, p. 27, table 2.a)]. However, other authors, including Griliches (1990) and Wagner \& Wakeman (2016), have endorsed the use of patent count data. Therefore, while we acknowledge that patent counts are subject to certain limitations when used to account for technological change, such data are a useful and frequently used measure for the innovative activity of firms, sectors, and countries.

The patent counts used in this study were created originally by the EPO and subsequently aggregated to the country-level by Eurostat. Every newly filed patent at the EPO is classified according to the Cooperative Patent Classification (CPC), recently enriched by the introduction of

\footnotetext{
${ }^{11}$ Bulgaria and Romania joined the EU and, thus, the EU ETS, in 2007, so data for these two countries are only available thereafter. Norway joined the EU ETS in 2008, so only a reduced set of data is available.
} 
the new patent class, Y02, for patents providing CCMTs (see information in Table A-1). Here, we focus specifically on subclass Y02E, which includes technologies for the reduction of GHG emission, related to energy generation, transmission or distribution. ${ }^{12}$ We also use patents from class Y02, to conduct a robustness check for our results.

An initial inspection of data for the Y02 patents shows several peculiarities. The most striking is the heterogeneity in the number of patent counts per country. In our sample, twelve countries $^{13}$ account for most CCMT patent applications at the EPO and together account for over $60 \%$ of overall patent applications. Additionally, we identify a strong outlier - Germany (as noted by Dechezleprêtre et al., 2011), which accounts for more than three times the mean number of applications than the country ranked second, France (Figure 1 shows the distribution of patents by country, for class Y02, and subclasses Y20E and Y20C). We specifically discuss and consider this when modeling the relationship between innovative behavior and the oversupply of certificates.

(Insert figure 1 here

Figure 1: Patent Counts per Country)

\subsection{The explanatory variables}

Table 1 provides a detailed overview of the variables used, including their descriptive statistics, units of measurement and labels.

\section{(Insert table 1 around here)}

Explanatory variables must fulfill different tasks in regression equations. In our case, we identify the following groups of explanatory variables to address different features of the number of patent applications per country. As we are interested in measuring the impact of the policy on

\footnotetext{
${ }^{12}$ Even though Y02C class technologies find appliance in the energy sector, they may also be employed in other sectors, but a clear distinction is not given. We include the Y02C class in Figure 1.

${ }^{13}$ Austria, Belgium, Germany, Denmark, Spain, Finland, France, United Kingdom, Italy, the Netherlands, Norway, and Sweden.
} 
patent counts, our "core" variables are the oversupply of allowances and the binary variable controlling for policy changes between the two trading phases.

Because we are interested in the role of EUA oversupply and major policy changes on patenting behavior, we examine these variables first. In this study, the stock of oversupply is defined as the annual accumulated number of excess EUAs allocated to each member state in the market, i.e., the difference between the total number of allowances allocated in the market and total emissions in each respective year accumulated over the period. In addition, and to ensure policy features, such as the cancelation of allowances from the first phase, are correctly taken into account in the second phase, the stock of oversupply is calculated separately for the two trading phases. We opted for this calculation as firms access not only their own oversupply but also that of the market as whole, since a common market place exists. It quickly becomes apparent that during the period most countries operating under the EU ETS were able to build up a sizable oversupply. ${ }^{14}$

Furthermore, and in order to specify correctly the impact of policy stringency on patenting behavior and so as not to mistakenly attribute the effects of other influences to these variables, we use a broad set of controls. We use lagged business enterprise and government R\&D spending, ${ }^{15}$ measured as percentage of Gross Domestic Product (GDP), and the number of workers with tertiary education, given that these variables have been shown to be highly influential in determining innovation output (Griliches 1984).

\footnotetext{
${ }^{14}$ Full data on oversupply by countries is provided in EU Emissions Trading System (ETS) data viewer (European Environment Agency) https://www.eea.europa.eu/data-and-maps/dashboards/emissionstrading-viewer-1 ('allowances and emissions')
}

${ }^{15}$ We also checked for overall patenting trends in our regressions, using overall patent counts divided by the population of a country for a given year. However, this trend variable is highly correlated with business enterprise R\&D and, hence, caused severe multicollinearity problems in our regressions. When introduced separately, the variable presented high statistical significance and the expected positive impact on CCMTs. However, we opted to use business enterprise $R \& D$ expenditure because of its well-known impact on patenting activity and also because the use of either of the two variables did not modify the outcomes of our estimates. (The Regressions using the patenting trend available upon request). 
We introduce an additional set of covariates to capture the economic performance of countries during the period of observation and respective industry size. We use these variables because it is has been shown that large industrial economies tend to have the most burdensome environmental problems and policies (Meyer, 1992, p.35). Therefore, a relation between economic performance and CCMTs, as a means for reducing compliance costs, may exist. These variables are industry indicators for the three main sectors - Mining and Quarrying (NACE B), Manufacturing (NACE C), and Energy (NACE D) - covered by the policy and annual GDP growth rates. All variables measuring a country's and a sector's economic performance are lagged one year, because it seems reasonable to think that last year's economic outcomes influence this year's patent rates, given the time it takes for an innovation to become eligible for patenting. ${ }^{16}$ As shown earlier, energy related patents make up the clear majority of CCMT patents. In line with Edenhofer et al. (2012), and to incorporate this circumstance, we introduce the share of energy from renewable sources into the equations, as this is an obvious indication of "green" technological change. ${ }^{17}$

The two trading phases are characterized by major policy changes (see section 2 above; Bel and Joseph, 2015). For instance, "penalties for violations increased from $€ 40$ per ton of $\mathrm{CO}_{2}$ in the first phase to $€ 100$ in the second phase (...). The system's cap was tightened for Phase II (200812)" (Schmalensee and Stavins, 2017, p. 581). A regression equation analyzing these policy shifts needs to take these circumstances into consideration. For this reason, we created a dummy variable equal to 1 for years belonging to the second trading period and equal to zero for the years belonging to the first period. This allows us to identify whether patenting behavior changed during the shift from phase one to two. Considering that the second trading phase tightened emission caps and

\footnotetext{
${ }^{16}$ Recall we do not use a lagged form for employment in the tertiary sector, as we believe the character of this variable does not make it necessary.

${ }^{17}$ We tried - alternatively - the share of renewable installed capacity, and obtained the same results from the estimations. (Results available upon request).
} 
reduced the share of certificates allocated free of charge, this policy shift is equivalent to an increase in policy stringency and should have a positive effect on patenting behavior.

\section{Methodology}

To measure empirically the impact of the excess supply of EUAs, the following reduced form equations are estimated, using a count data approach:

$$
\begin{aligned}
& \text { Patents }_{i, t}=\alpha+\beta_{1} \text { L.eua }_{\text {ovs } t-1}+\beta_{2} \text { dummy_ets }_{i, t}+\beta_{3} \text { empl }_{i, t}+ \\
& \beta_{4} \text { L.BERD }_{i, t-1}+\beta_{5} \text { L.GORD }_{i, t-1}+\beta_{6} \text { L. nace }_{b_{i, t-1}}+\beta_{7} \text { L. nace }_{c_{i, t-1}}+ \\
& \beta_{8} \text { L. nace }_{d_{i, t-1}}+\beta_{9} \text { L.GDP }_{\text {growth }_{i, t-1}}+\beta_{10} \text { L.renew }_{i, t-1}+\mu_{i, t}+ \\
& \varepsilon_{i, t}
\end{aligned}
$$

where the dependent variable Patents is a count of Y02E patent applications registered at the EPO (note, Patents serves as a placeholder for the Y02 class in the robustness check). The core variables in our estimations are lagged ena_ovs, which represents the annual accumulated oversupply of EUAs, and the dummy_ets, which reflects policy changes during the transition from Phase I to Phase II (with values zero for years in the first trading period, and 1 in the second period). The other variables (as defined in the previous section) are the following: ${ }^{18}$ empl is the number of workers in the tertiary sector; L.BERD and L.GORD are the lagged R\&D expenditures. L.nace_b, - $c$, and $-\_d$ are lagged economic industry indices for the main sectors covered by EU ETS. L.GDP_growth is the lagged percentage change in GDP. renew represents the lagged share of renewable energies in the gross final energy consumption. $\mu_{i, t}$ is the between-entity error and $\varepsilon_{i, t}$ is the within-entity error term of the random effect specification. Subscripts $i$ and $t$ define the crosssection and the time dimension of our data.

\footnotetext{
${ }_{18}$ We have chosen a one-year time lag following Pakes and Griliches (1984). These authors compute a mean lag of 1.6 years as their mean R\&D project gestation lag. We believe that given that more than three decades have passed since Pakes and Griliches (1984), it is sensible to assume that technological development will have shortened that lag.
} 
We use negative binomial random effects estimates, ${ }^{19}$ whereby the mean equals $\mu$, and the variance can increase by parameter $\alpha>0$, allowing for unobserved heterogeneity across the sample. Hence, the first two moments of the negative binomial distribution are given by:

$$
\begin{gathered}
E[y \mid \mu, \alpha]=\mu \\
V[y \mid \mu, \alpha]=\mu(1+\alpha \mu)
\end{gathered}
$$

Recall that the variance now exceeds the mean, thereby addressing the problem of overdispersion of the data and allowing unobserved heterogeneity to alter the mean-variance relationship. Moreover, we use random effects due to short panel properties and the corresponding incidental parameter problem (Cameron \& Trivedi 2013, Hilbe 2011, Greene 2007). ${ }^{20}$ Furthermore, we use the exposure variable GDPvol,, measured in this study as GDP in volumes, to account for country size differences. To obtain robust standard errors for our coefficient estimates bootstrapping with 1000 replications is used. A more detailed discussion regarding the robustness of our estimates and resulting bias can be found in the appendix along with bias-corrected confidence intervals (Table A4 and A5). We use maximum likelihood as our estimation method.

\section{Estimation Results}

In line with the methodology outlined above, we performed the estimations for the Y02E subclass (Table 2). The overall model fit, given by the $\chi^{2}$ statistic of the Wald test, rejects the $\mathrm{H}_{0}$ of joint statistical insignificance. We use a likelihood-ratio test to check if the panel structure is justified or whether a pooled estimator with constant over-dispersion should be used. We reject the $H_{0}$ of constant over-dispersion; hence, the panel structure chosen for our model is valid. Additionally,

\footnotetext{
${ }^{19}$ We do not use a Poisson regression because it is too restrictive in the case of our data (Hausman et al. 1984; Cameron and Trivedi 2005; Johnstone et al. 2010). See Figure A1 in the appendix.

${ }^{20}$ As Dhaene and Jochmans (2015: 992) explain, fixed-effect approaches typically are faced with the problem that maximum-likelihood estimates are not consistent when the number of units increases but the number of observations per unit is fixed. They also stress that the incidental-parameter problem is most severe in short panels.
} 
we performed a multicollinearity test. This shows that all variance inflation factors are well below five, suggesting that there are no problems of multicollinearity in our regressions (Table A2). The overall sample included 217 observations; however, due to the use of lagged variables the sample size was reduced by 28 observations in the regressions.

(Insert table 2 around here)

\subsection{EUA oversupply and policy changes}

The main purpose of the empirical exercise is to verify if the impact of the certificate oversupply is robust even when applying a broad set of controls and if policy changes related to higher stringency affect YE02 patenting. If we inspect the estimates corresponding to oversupply (eua_ovs), this would appear to be the case. The outcomes show high significance levels (at the $1 \%$ level). The sign associated with every equation is, as expected, negative, indicating that an increase in market oversupply reduces the overall number of "green" patents. Following the same intuition, the dummy variable indicating the shift between the two trading phases, in common with the oversupply variable, shows a high statistical significance at the $1 \%$ level, but it presents a positive impact on CCMT patents. This implies that the shift from phase I to phase II can be considered as having been a positive stimulus towards more environment-friendly technological change, as the second phase increased the stringency of the EU ETS. These are the overt conclusions to be drawn from the statistical analysis; however, the implications of these results are complex.

Our results show that "green" technology change is closely related to the EU ETS, when technology change is measured in terms of patent applications registered at the EPO. Yet, the current situation of the EU ETS, characterized by an excess supply of allowances, cannot be considered conducive to technology change; a lax EU ETS does not increase innovation as much as a stringent EU ETS. This means that the oversupply of allowances in the market causes the policy to lose much of its potential for fostering the technological change needed to achieve the EU's ambitious climate goals. This is all the more evident when considering the effects of policy 
changes expressed using the dummy variable, since higher stringency leads to more "green" patenting activity and, finally, to an increase in environment-friendly production.

\subsection{Results for control variables}

The variables known to have an impact on innovation are statistically significant in the estimations; that is, as expected, they positively influence the patenting of CCMTs. Tertiary employment and business enterprise $\mathrm{R} \& \mathrm{D}$ expenditure (L.BERD) have a positive impact on the number of patent applications, at the 1\% level. However, the same is not true of government R\&D expenditure - the coefficient for L.GORD being statistically insignificant.

As for overall economic performance (L.GDP_growth) and sector-specific performance (L.nace_b,c,d), our results suggest that patenting in the Y02E category is not affected by the expansion of a country's economy in the previous year. However, if we examine the sector-specific economic performance this picture changes. We do not find a statistically significant relationship between higher activity levels in the mining and quarrying sector (nace_b) and patent activity, and we record only a small negative impact (with weak statistical significance, at the $10 \%$ level) for the manufacturing sector (nace_c). In contrast, the coefficient measuring the impact of the performance of the energy sector shows high statistical significance and a positive relationship with respect to "green" patenting activities. The use of the share of energy from renewable sources is statistically insignificant, indicating that it does not affect green patenting in our sample.

\subsection{Robustness check}

To check the robustness of our results we estimated the same equation but here for all patents in the Y02 class. Table 3 presents the results of this estimation. The overall fit and robustness of the estimation are the same as those reported for Y20E. This is true of all the coefficients, signs and statistical significances of all the explanatory variables, with just one minor exception: the coefficient for the manufacturing sector (nace_c) - which was weakly significant - is now statistically 
insignificant. Thus, we can state that the results of our estimation are robust to the inclusion of all other Y02 patent types, besides those of the Y02E subclass.

\section{(Insert table 3 around here)}

In Table A3 in the appendix we also show the estimation results for Y02E and Y02 patent types using fixed effects, because the Hausman test for random and fixed effects could not be estimated properly for all model specifications. The table shows that when using fixed effects the results do not vary significantly and the main outcomes related to our key variables remain unchanged. We conducted an additional robustness test by replacing the binary variable with time effects. The two columns furthest to the right in Table A3 display the results from these estimations. The coefficient signs are the same and the significance differs only slightly. Interestingly, we find strong positive effects in the first two years of the second phase (2009 and 2010), but that the positive effect erodes thereafter.

\subsection{Quantification of impact of oversupply and the policy shift}

In this subsection, we quantify the impacts obtained in the estimations above. Figure 2 shows the impact of different degrees of oversupply, and the shift from Phase I to Phase II, on the Y02E subclass, so as to shed more light on the effects of the EU ETS. As such, we are able to predict the average number of CCMTs under the different scenarios of overall oversupply ${ }^{21}$ in the market and between the two trading phases, by employing our estimation results in Table 2 . All the other covariates in our regressions are allowed to vary, as they do in our sample (Stata Corp LP, 2013). First, it is apparent that there is a clear negative relationship between oversupply and the associated number of patent applications; and, second, that the predicted number of patent applications varies considerably between the two phases as expressed by the upward shifts in the respective curves (red vs. blue). ${ }^{22}$

\footnotetext{
${ }^{21}$ We decided to use a range from $-1000 \mathrm{MgT}$ to $7000 \mathrm{MgT}$, since these two values mark the extreme values of accumulated oversupply in our data sample.

22 Recall that we constructed Figure 2 by including situations in which the oversupply of permits in the market is negative. In those circumstances, however, we need to consider that going from an oversupply to
} 
(Insert around here

Figure 2: Estimated Number of Y02E patents for given levels of certificate oversupply and Phase I \& II)

In addition to the graphical representation of the effects of oversupply and the transition from Phase I to II, Table 4 presents numerical examples of these effects. As can be seen, the shift between trading phases is associated with an increase of around $35 \%$ in the case of the $\mathrm{Y} 02 \mathrm{E}$ category (we also include the corresponding calculation for $\mathrm{Y02}$, as this is obtained directly from the results in Table 3), when evaluated as the mean of the accumulated oversupply. Similarly, we are also interested in determining the number of patent applications we can expect if the oversupply were to be reduced. By way of example, we calculated the expected increase in patent applications in both the Y02E subclass and the Y02 class in the case of a reduction in oversupply from its mean to a balanced oversupply, that is, an oversupply that equals zero. For this numerical example, the resulting increases for both patent categories and phases are around 9\%, which highlights the strong negative impact of oversupply on patenting behavior. Recall the fact that the Y02E subclass accounts for over $90 \%$ of all CCMT patents explains the very small variations between the Y02E and Y02 patent types.

\section{(Insert table 4 around here)}

The situation is exacerbated by other modes of compliance that are available under the system, specifically, the Kyoto-offsets. These additional certificates of negligible price undermine even further the incentives to innovate by reducing the cost of compliance for market participants.

Our findings show that the EU ETS, as a market-based regulation, has an impact on the countries' levels of innovative activity (in terms of number of patents for CCMTs); however, so do policy failures. The patents in the countries affected by the system are not responding to the policy as expected, owing, on the one hand, to the negative impact of EUA oversupply on patent applications at the EPO, and, on the other, to policy changes related to greater stringency positively

\footnotetext{
a permit shortage would not have a linear impact on innovation, but rather it could give rise to a marked non-linear response of innovation to climate policy stringency. If this were the case, we can consider the linear extrapolation in Figure 2 to be a lower bound, conservative estimate of the possible change.
} 
affecting "green" patenting. Thus, in line with Porter \& van der Linde’s (1995) claim, the stringency of the policy plays a vital role in determining whether an environmental policy will spur technological change. Here, we can assume that a shortage of EUA allowances in the market might serve to encourage innovation (Figure 2).

\section{Conclusion}

In this study we evaluate the relationship between the sizable oversupply of EUAs and a policy shift marked by the transition from Phase I to Phase II under the EU ETS on technological change, on the one hand, and its impact on "green" patenting, on the other. To do so, we use patent count data for all CCMTs and CCMTs related to energy generation, transmission and distribution. According to our results, the expected negative impact of this oversupply on technological change (with respect to the stringent policy) seems to be confirmed. Thus, stakeholders under the EU ETS do consider their emissions when determining their innovative activity. In the same vein, they likely do so with respect to policy changes implementing greater stringency, as these generated a sizeable increase in patenting activity when controlling for other economic factors. However, we also take into account policy failures, in this case the oversupply of certificates. The latter is clearly apparent in the strong negative impact of the excess supply of EUAs on the number of CCMT patent applications (compared, that is, with a stringent policy). Therefore, two contrary but not mutually exclusive effects have been identified as operating under the trading system.

From a policy perspective, we ought to acknowledge that the EU ETS, as lax as it was, may well have been the only acceptable option for policy makers at the time the system was designed and implemented. As such, oversupply may represent the toll paid to ensure the initial system was approved and implemented, on the grounds that it was better than no system at all. Likewise, the fact that the EU has attempted to increase its stringency over the years may have been the necessary outcome of what might be seen as a system based on trial-and-error. That said, we believe that several measures could be implemented to counter the negative impact of oversupply. Although 
the EC introduced the "back-loading" of new allowances in the third trading period, a rigorous cancelling of allowances would help put the policy back on the right track and ensure the rethinking of production in a more environment-friendly way. A second approach, and one contemplated by the EC, involves the introduction of a market stability reserve. In principle, this reserve should guarantee that a certain threshold of excess EUAs (833 million allowances) is not passed. Were it to be exceeded, the market stability reserve would deduct the excess amount from future auction volumes (European Commission, 2014b). Even though this approach sounds promising, its introduction has been postponed until 2021, the start of the fourth trading period.

In addition, given that the market for EUAs adheres to the fundamentals of supply and demand in fixing prices, it is prone to external shocks such as the recent economic crisis that seriously hampered the systems credibility as a driver of low-carbon technologies. In order for the market to be less vulnerable to shocks, a price floor could be installed guaranteeing a minimum price for EUAs and, thus, providing the policy with both greater stringency and stability. Such a price floor would have to be sufficiently high to spur innovation, but low enough to avoid a crowding-out of production and a loss of competitiveness in the EU. These measures would likely be opposed by the industrial sector, but they would put the policy back on track. Furthermore, and given the positive impact of the increase in policy stringency represented by the shift from Phase I to II, policymakers are urged to revise existing and future emission caps, to firmly place the EU on a low-carbon pathway, since this transition in our data sample is related to a marked increase in "green" technological change.

From a scholarly perspective, our results suggest that market-based regulations have an impact on innovative behavior at the country level and when they are well designed such regulations can spur innovation, as higher stringency seems to influence overall patent counts (as highlighted in our data).

Overall, the results presented in this research are robust to a broad set of controls and show the expected relationship. We have shown that oversupply has serious impacts on overall patenting 
behavior in the field of CCMTs. Future research needs to focus on comparing market-based regulations, such as the EU ETS, and a suitable counterfactual in order to measure what might have occurred if there had not been such an excess of allowances.

Our study is subject to limitations, among which we should mention the shortcomings involved from using quantitative patent data (without considering the adoption of innovations or the quality of patents). Moreover, we use country-level data rather than firm-level data. Yet, our analysis has allowed us to identify the overall impact of an excess supply of certificates on "green" patenting. Future research, however, should seek to use firm-level data. More specifically, the matching of single firms by patents and their respective shortage/oversupply of allowances could be used to cross-validate our findings. Furthermore, future research would benefit from taking into account intercountry emission trading.

Acknowledgments: We acknowledge financial support from the Spanish Ministry of Economy and Competitiveness (project ECO2016-76866-R), and the Catalan government (SGR2014-325). None of the funding sources had any involvement in any stage of this research. We thank Jordi Teixidó for useful comments, and two anonymous referees for their detailed comments. 


\section{APPENDIX}

(Insert Figure A1: Empirical Distribution of Y02 patent counts, Negative Binomial Distribution, and Poisson Distribution)

(Insert table A1)

(Insert Table A2)

(Insert Table A3)

(Insert Table A4)

(Insert Table A5)

Notes to Tables A4 and A5:

Since we are using bootstrapping in order to obtain robust estimates for our standard errors, we need to examine more closely the bootstrap results for our two main regressions in Tables 2 and 3. The main idea underpinning bootstrapping is to estimate the standard error by drawing repeated bootstrap samples from the original data by using sampling with replacement and by fitting the model repeatedly. In our case, we use 1000 bootstrap replications of our data sample. As the model is fitted over and over again, a bias estimate of the observed statistic and the bootstrap estimates can be constructed (Stata Corp., 2015) along with bias-corrected confidence intervals (CI). As can be seen in Tables A4 and A5, some coefficient estimates of our main equation exhibit a slight bias, therefore, we are interested in knowing if these estimates still lie within a CI that takes the bias into account. For this reason, the bias-corrected CI intervals along with their estimated bias are presented here. As can be seen in Tables A4 and A5, even though bias is present for some estimates, all the statistically significant coefficients of our main estimations in Tables 2 and 3 lie well inside the bias-corrected CI allowing us to use them for further inference and predictions. 
Table 1: Variable Overview

\begin{tabular}{|c|c|c|c|c|c|c|}
\hline Variables & Description & $\mathrm{N}$ & mean & sd & $\min$ & $\max$ \\
\hline Y02E & $\begin{array}{l}\text { Number of Patent application at the EPO } \\
\text { for the Y02E category }\end{array}$ & 217 & 72.25 & 161.3 & 0 & 1,017 \\
\hline Y02 & $\begin{array}{l}\text { Number of Patent application at the EPO } \\
\text { for the Y02 category }\end{array}$ & 217 & 75.47 & 167.7 & 0 & 1,056 \\
\hline GDP_growth & $\begin{array}{l}\text { Percentage change of GDP on previous } \\
\text { year }\end{array}$ & 217 & 1.524 & 4.223 & -17.70 & 11 \\
\hline Renew & $\begin{array}{l}\text { Share of renewable energy in gross final } \\
\text { energy consumption }\end{array}$ & 217 & 15.11 & 13.27 & 0.300 & 64.80 \\
\hline nace_b & $\begin{array}{l}\text { Volume index of production for the mining } \\
\text { and quarrying sector; data adjusted by } \\
\text { working days }\end{array}$ & 217 & 108.3 & 21.03 & 61.91 & 224.8 \\
\hline nace_c & $\begin{array}{l}\text { Volume index of production for the } \\
\text { manufacturing sector; data adjusted by } \\
\text { working days }\end{array}$ & 217 & 103.4 & 10.06 & 65.54 & 130.0 \\
\hline nace_d & $\begin{array}{l}\text { Volume index of production for the energy } \\
\text { sector; data adjusted by working days }\end{array}$ & 217 & 98.91 & 7.515 & 75.87 & 119.1 \\
\hline BERD & $\begin{array}{l}\text { Business enterprise R\&D expenditure as } \\
\text { percentage of GDP }\end{array}$ & 217 & 0.915 & 0.690 & 0.0600 & 2.680 \\
\hline GORD & $\begin{array}{l}\text { Governmental R\&D expenditure as } \\
\text { percentage of GDP }\end{array}$ & 217 & 0.194 & 0.0887 & 0.0100 & 0.410 \\
\hline GDPvolume & $\begin{array}{l}\text { Gross Domestic Product at current prices, } \\
\text { million euros }\end{array}$ & 217 & 471,488 & 688,090 & 5,142 & $2.758 \mathrm{e}+06$ \\
\hline eua_ovs & $\begin{array}{l}\text { Yearly accumulated oversupply of EUA in } \\
\text { the market in Mgt. }\end{array}$ & 217 & 2,043 & 2,356 & $-1,088$ & 7,023 \\
\hline Empl & $\begin{array}{l}\text { Total Employees with tertiary education } \\
\text { (levels 5-8) from age } 25-64 \text { in thousands }\end{array}$ & 217 & 2,073 & 2,771 & 20 & 10,889 \\
\hline dummy_ets & $\begin{array}{l}\text { Dummy for the shift from phase one to } \\
\text { phase two of the EU ETS }\end{array}$ & 217 & 0.686 & 0.465 & 0 & 1 \\
\hline Number of countries & & 28 & 28 & 28 & 28 & 28 \\
\hline
\end{tabular}


Table 2: Estimation Results for the Random Effects Negative Binomial - Y02E

\begin{tabular}{|c|c|}
\hline & RE regression for $\mathrm{Y} 02 \mathrm{E}$ \\
\hline & $(2)$ \\
\hline \multirow[t]{2}{*}{ L.eua_ovs } & $-4.35 \mathrm{e}-05^{* * *}$ \\
\hline & $(1.43 e-05)$ \\
\hline \multirow[t]{2}{*}{ 1.dummy_ets } & $0.298^{* * *}$ \\
\hline & $(0.0579)$ \\
\hline \multirow[t]{2}{*}{ empl } & $8.44 \mathrm{e}-05^{* * *}$ \\
\hline & $(3.28 \mathrm{e}-05)$ \\
\hline \multirow[t]{2}{*}{ L.BERD } & $0.919 * * *$ \\
\hline & $(0.179)$ \\
\hline \multirow[t]{2}{*}{ L.GORD } & -0.935 \\
\hline & $(0.887)$ \\
\hline \multirow[t]{2}{*}{ L.nace_b } & -0.000893 \\
\hline & $(0.00232)$ \\
\hline \multirow[t]{2}{*}{ L.nace_c } & $-0.00609 *$ \\
\hline & $(0.00366)$ \\
\hline \multirow[t]{2}{*}{ L.nace_d } & $0.0157 * * *$ \\
\hline & $(0.00543)$ \\
\hline \multirow[t]{2}{*}{ L.GDP_growth } & 0.000799 \\
\hline & $(0.0105)$ \\
\hline \multirow[t]{2}{*}{ L.renew } & 0.00142 \\
\hline & $(0.00658)$ \\
\hline \multirow[t]{2}{*}{ Constant } & $-11.05^{* * *}$ \\
\hline & $(1.130)$ \\
\hline Observations & 189 \\
\hline Number of Panels & 28 \\
\hline $\mathrm{F}$ & 132.1 \\
\hline Panel vs Pooled & 260.1 \\
\hline Log-Likelihood & -588.8 \\
\hline
\end{tabular}

Bootstrap Standard errors in parentheses

$$
\text { *** } \mathrm{p}<0.01, * * \mathrm{p}<0.05
$$

Note: A brief discussion of the use of bootstrap technique along with bias corrected confidence intervals can be found in the appendix (tables A4 \& A5) 
Table 3: Estimation Results for the Random Effects Negative Binomial - Y02

\begin{tabular}{|c|c|}
\hline & RE regression for $\mathrm{Y} 02$ \\
\hline & (1) \\
\hline \multirow[t]{2}{*}{ L.eua_ovs } & $-4.23 \mathrm{e}-05^{* * *}$ \\
\hline & $(1.49 \mathrm{e}-05)$ \\
\hline \multirow[t]{2}{*}{ 1.dummy_ets } & $0.303 * * *$ \\
\hline & $(0.0509)$ \\
\hline \multirow[t]{2}{*}{ empl } & $8.12 \mathrm{e}-05^{* * *}$ \\
\hline & $(2.74 \mathrm{e}-05)$ \\
\hline \multirow[t]{2}{*}{ L.BERD } & $0.897 * * *$ \\
\hline & $(0.186)$ \\
\hline \multirow[t]{2}{*}{ L.GORD } & -0.820 \\
\hline & $(0.882)$ \\
\hline \multirow[t]{2}{*}{ L.nace_b } & -0.000579 \\
\hline & $(0.00231)$ \\
\hline \multirow[t]{2}{*}{ L.nace_c } & -0.00588 \\
\hline & $(0.00374)$ \\
\hline \multirow[t]{2}{*}{ L.nace_d } & $0.0152 * * *$ \\
\hline & $(0.00506)$ \\
\hline \multirow[t]{2}{*}{ L.GDP_growth } & 0.000990 \\
\hline & $(0.0105)$ \\
\hline \multirow[t]{2}{*}{ L.renew } & 0.00199 \\
\hline & $(0.00627)$ \\
\hline \multirow[t]{2}{*}{ Constant } & $-11.06^{* * *}$ \\
\hline & $(1.230)$ \\
\hline Observations & 189 \\
\hline Number of Panels & 28 \\
\hline $\mathrm{F}$ & 143.7 \\
\hline Panel vs Pooled & 261.2 \\
\hline Log-Likelihood & -594.6 \\
\hline
\end{tabular}

Bootstrap Standard errors in parentheses

$$
* * * \mathrm{p}<0.01, * * \mathrm{p}<0.05
$$

Note: A brief discussion of the use of bootstrap technique along with bias corrected confidence intervals can be found in the appendix (table A3 \& A4) 
Table 4: Estimated Changes in Patent Counts due to Oversupply Reduction and Transition from Phase I to II

Oversupply Reduction (From Mean Oversupply to Balanced Supply)

\begin{tabular}{lcccc}
\hline & \multicolumn{2}{c}{ Y02E Patents } & \multicolumn{2}{c}{ Y02 Patents } \\
& Phase I & Phase II & Phase I & Phase II \\
Mean Oversupply (2000 MgT) & 61.23 & 82.45 & 62.37 & 84.44 \\
Balanced Supply ( 0 Mgt) & 66.8 & 90 & 67.9 & 91.9 \\
$\begin{array}{l}\text { \% Change Mean Oversupply to Balanced } \\
\text { Supply: }\end{array}$ & $\mathbf{9 . 1 \%}$ & $\mathbf{9 . 1 6 \%}$ & $\mathbf{8 . 9 \%}$ & $\mathbf{8 . 8 \%}$ \\
\hline
\end{tabular}

Transition Phase I to II given the Mean Oversupply

\begin{tabular}{|c|c|c|c|}
\hline & Phase I & Phase II & $\begin{array}{l}\text { Mean \% Change } \\
\text { Phase I to Phase II }\end{array}$ \\
\hline \multicolumn{4}{|l|}{ Y02E Patents } \\
\hline Mean Oversupply (2000 MgT) & 61.23 & 82.45 & $34.64 \%$ \\
\hline \multicolumn{4}{|l|}{ Y02 Patents } \\
\hline Mean Oversupply (2000 MgT) & 62.37 & 84. 44 & $35.38 \%$ \\
\hline
\end{tabular}

Source: Based on estimations Tables 2 and 3, and own calculations 
Figure 1. Patent Counts per Country

Figure 1: Patent Counts per Country

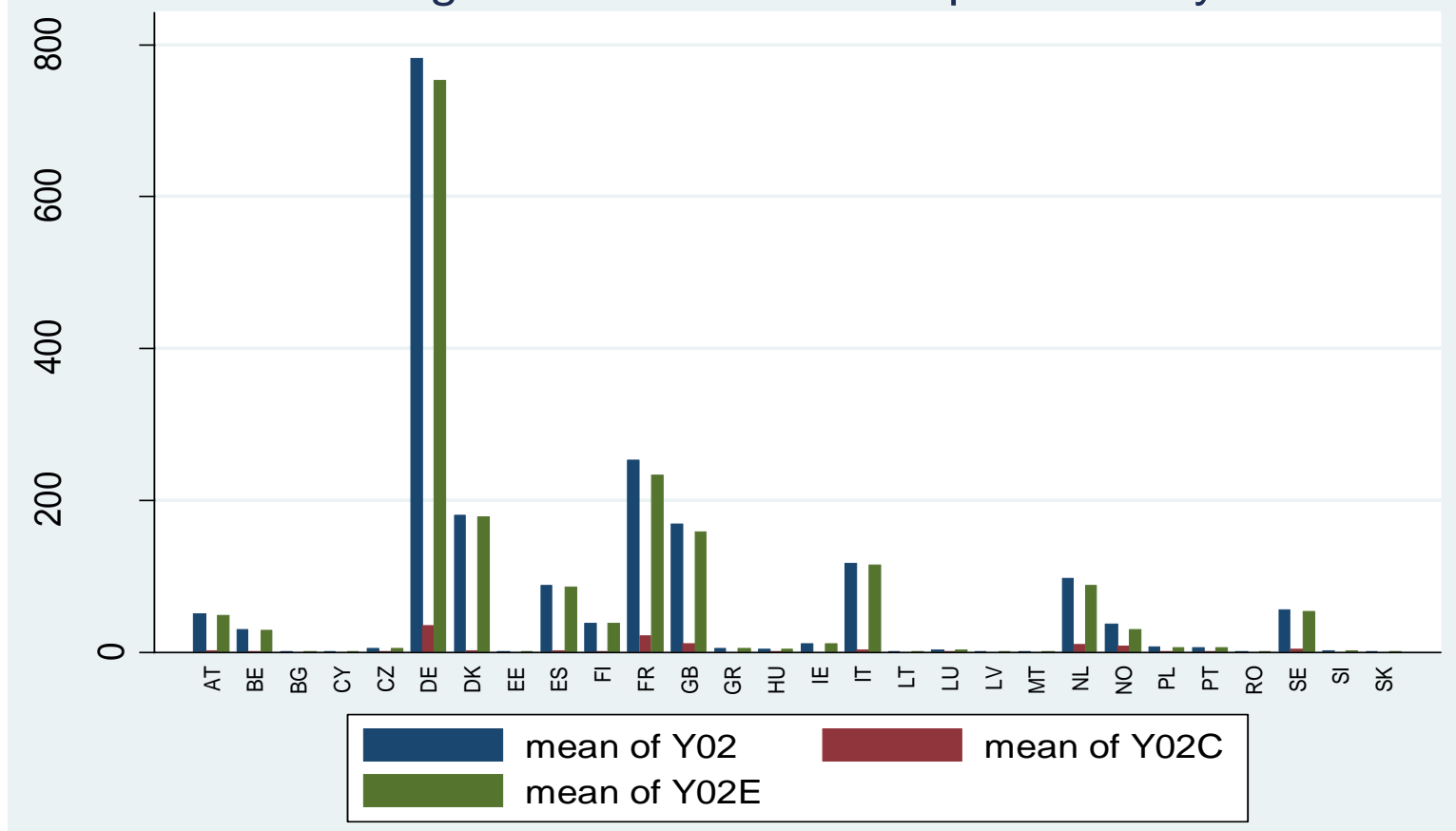


Figure 2: Estimated Number of Y02E patents for given levels of certificate oversupply and Phase I and II

Fig.2: Pred. \# of Y02E Patents vs the EUA Oversupply with $95 \% \mathrm{Cls}$ \# of Y02E Patents vs OVS at Range $-1000-+7000 \mathrm{Mgt}$ (Phase I and II)

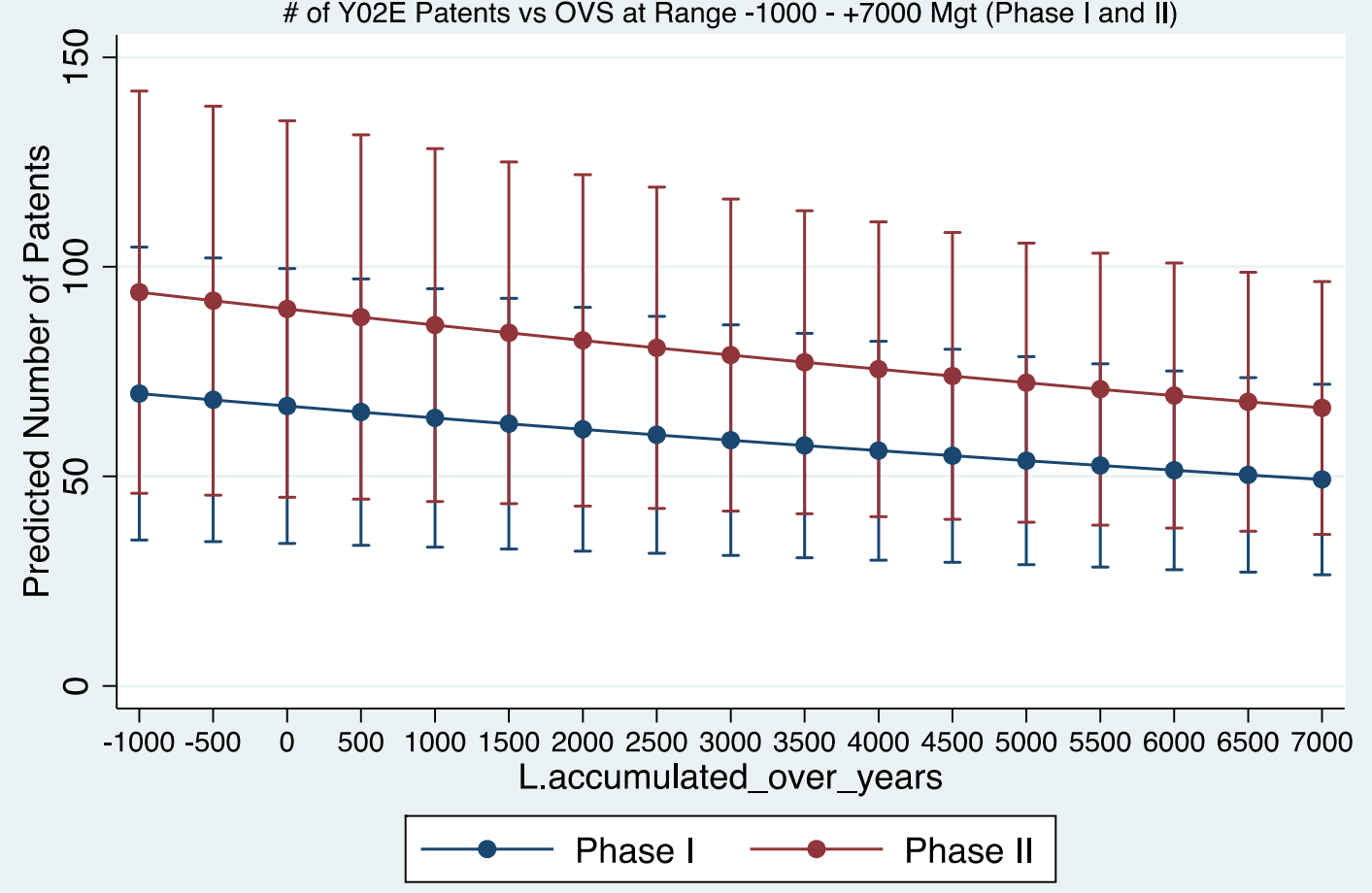

Source: Own Calculations based on estimation results shown in table 2 
Table A1: The Y02E patent subclass (CPC classification)

\begin{tabular}{l|l|l}
\hline Patent Class & Definition & Examples \\
\hline Y02 & Climate Change Mitigation Technologies \\
\hline
\end{tabular}

Subclass Y02E

\begin{tabular}{l|l|l}
\hline Y02E & $\begin{array}{l}\text { Reduction of GHG emissions related to energy generation, transmission or } \\
\text { distribution }\end{array}$ \\
\hline Y02E10/00 & $\begin{array}{l}\text { Energy generation through } \\
\text { renewable energy sources }\end{array}$ & $\begin{array}{l}\text { Geothermal Energy / Hydro Energy / } \\
\text { Energy from Sea / Photovoltaic } \\
\text { (PV)Energy / Thermal-PV hybrids / Wind } \\
\text { Energy }\end{array}$ \\
\hline Y02E 20/00 & $\begin{array}{l}\text { Combustion technologies with } \\
\text { mitigation potential }\end{array}$ & $\begin{array}{l}\text { Combined combustion / Technologies for } \\
\text { a more efficient combustion or heat usage }\end{array}$ \\
\hline Y02E 40/00 & $\begin{array}{l}\text { Technologies for an efficient } \\
\text { electrical power generation, } \\
\text { transmission or distribution }\end{array}$ & $\begin{array}{l}\text { Flexible AC transmission systems / Active } \\
\text { power filtering / Reactive power } \\
\text { compensation }\end{array}$ \\
\end{tabular}


Table A2: Multicollinearity

\begin{tabular}{ll} 
Variable: & VIF \\
\hline L.eua_ovs & 1.13 \\
empl & 1.39 \\
L.BERD & 1.46 \\
L.GORD & 1.35 \\
L.GDP_growth & 1.44 \\
L.nace_b & 1.51 \\
L.nace_c & 1.39 \\
L.nace_d & 1.27 \\
L.renew & 1.46 \\
dummy_ets & 1.30 \\
\hline
\end{tabular}

Mean VIF $\quad 1.37$ 
Table A3: Estimation Results for (1) the Fixed Effects Negative Binomial (central model), and (2) with inclusion of time effects.

\begin{tabular}{|c|c|c|c|c|}
\hline & $\begin{array}{l}\text { FE regression } \\
\text { for } Y 02 E\end{array}$ & $\begin{array}{l}\text { FE regression } \\
\text { for } \mathrm{Y} 02\end{array}$ & $\begin{array}{l}\text { FE regression } \mathrm{Y} 02 \mathrm{E} \\
\text { with time effects }\end{array}$ & $\begin{array}{l}\text { FE regression for } \\
\text { Y02 with time effects }\end{array}$ \\
\hline & $(1)$ & $(2)$ & (3) & $(4)$ \\
\hline \multirow[t]{2}{*}{ L.eua_ovs } & $-5.00 \mathrm{e}-05^{* * *}$ & $-4.72 \mathrm{e}-05^{* * *}$ & $0.000418^{* *}$ & $0.000444 * *$ \\
\hline & $(1.44 \mathrm{e}-05)$ & $(1.46 \mathrm{e}-05)$ & $(0.000165)$ & $(0.000166)$ \\
\hline \multirow[t]{2}{*}{ 1.dummy_ets } & $0.231 * * *$ & $0.254 * * *$ & - & - \\
\hline & $(0.0662)$ & $(0.0718)$ & - & - \\
\hline \multirow[t]{2}{*}{2007} & - & - & 0.0142 & 0.00918 \\
\hline & - & - & $(0.100)$ & $(0.0981)$ \\
\hline \multirow[t]{2}{*}{2008} & - & - & 0.0261 & 0.0357 \\
\hline & - & - & $(0.146)$ & $(0.142)$ \\
\hline \multirow[t]{2}{*}{2009} & - & - & $1.229 * * *$ & $1.310^{* * *}$ \\
\hline & - & - & $(0.352)$ & $(0.352)$ \\
\hline \multirow[t]{2}{*}{2010} & - & - & $0.372^{* *}$ & $0.417 * *$ \\
\hline & - & - & $(0.149)$ & $(0.157)$ \\
\hline \multirow[t]{2}{*}{2011} & - & - & -0.192 & -0.184 \\
\hline & - & - & $(0.271)$ & $(0.267)$ \\
\hline \multirow[t]{2}{*}{2012} & - & - & $-1.133 * *$ & $-1.166^{* *}$ \\
\hline & - & - & $(0.559)$ & $(0.555)$ \\
\hline \multirow[t]{2}{*}{ empl } & 0.000143 & 0.000130 & $0.000159^{*}$ & 0.000139 \\
\hline & $(0.000148)$ & $(0.000170)$ & (9.10e-05) & $(8.79 \mathrm{e}-05)$ \\
\hline \multirow[t]{2}{*}{ L.BERD } & 0.458 & 0.443 & 0.423 & 0.417 \\
\hline & $(0.353)$ & $(0.365)$ & $(0.278)$ & $(0.287)$ \\
\hline \multirow[t]{2}{*}{ L.GORD } & -1.244 & -1.049 & -0.934 & -0.681 \\
\hline & $(1.890)$ & $(1.770)$ & $(-1.307)$ & $(-1.277)$ \\
\hline \multirow[t]{2}{*}{ L.nace_b } & -0.000981 & -0.000855 & $-5.46 e-05$ & 0.000130 \\
\hline & $(0.00252)$ & $(0.00256)$ & $(0.00289)$ & $(0.00236)$ \\
\hline \multirow[t]{2}{*}{ L.nace_c } & -0.00382 & -0.00383 & -0.00609 & -0.00638 \\
\hline & $(0.00449)$ & $(0.00497)$ & $(0.00688)$ & $(0.00650)$ \\
\hline \multirow[t]{2}{*}{ L.nace_d } & $0.0148^{* *}$ & $0.0143 * *$ & $0.0119^{* * *}$ & $0.0114 * * *$ \\
\hline & $(0.00595)$ & $(0.00606)$ & $(0.00315)$ & $(0.00358)$ \\
\hline \multirow[t]{2}{*}{ L.GDP_growth } & -0.00519 & -0.00415 & -0.0136 & -0.0113 \\
\hline & $(0.0103)$ & $(0.0108)$ & $(0.0118)$ & (0.0132) \\
\hline \multirow[t]{2}{*}{ L.renew } & 0.0205 & 0.0165 & 0.00977 & 0.00362 \\
\hline & $(0.0189)$ & $(0.0205)$ & $(0.0302)$ & $(0.0320)$ \\
\hline Constant & $\begin{array}{l}-10.75^{* * *} \\
-1.847\end{array}$ & $\begin{array}{l}-10.68 * * * \\
-2.152\end{array}$ & $\begin{array}{c}-10.37 * * * \\
(0.987)\end{array}$ & $\begin{array}{c}-10.30^{* * *} \\
(0.996)\end{array}$ \\
\hline Observations & 189 & 189 & 189 & 1889 \\
\hline \# of country_id & 28 & 28 & 28 & 28 \\
\hline Log-likelihood & -439.3 & -444.2 & -430.2 & -434.8 \\
\hline F & 110.4 & 173.2 & 331.9 & 351.5 \\
\hline
\end{tabular}


Table A4: Bootstrap Statistics for Y02E

Y02E Estimation

\begin{tabular}{cccccc} 
Y02E & $\begin{array}{c}\text { Observed } \\
\text { Coef. }\end{array}$ & Bias & $\begin{array}{c}\text { Bootstrap } \\
\text { Std. Err. }\end{array}$ & Bias Corrected 95\% CI \\
\hline L.eua_ovs & -0.0000435 & $-7.61 \mathrm{e}-07$ & 0.00001431 & -0.0000645 & $-5.57 \mathrm{e}-06$ \\
\hline 1.dummy_ets & 0.29753154 & -0.0900356 & 0.05798752 & 0.2864695 & 0.4454681 \\
\hline empl & 0.00008443 & -0.0000218 & 0.00003283 & 0.000063 & 0.0001832 \\
\hline L.BERD & 0.91935097 & 0.0043223 & 0.17971756 & 0.5384822 & 1.237758 \\
\hline L.GORD & -0.93454461 & 0.8202854 & 0.8872565 & -2.563458 & -0.5251221 \\
\hline L.nace_b & -0.00089334 & -0.0007591 & 0.002327 & -0.005792 & 0.0038918 \\
\hline L.nace_c & -0.00609018 & -0.0010591 & 0.00366387 & -0.0118202 & 0.003368 \\
\hline L.nace_d & 0.01567101 & 0.0005973 & 0.00543457 & 0.0029716 & 0.0249605 \\
\hline L.GDP_growth & 0.00079945 & 0.0016735 & 0.01050609 & -0.0218497 & 0.0201261 \\
\hline Lcons & -11.053 .978 & 0.7319055 & 1.1306838 & -13.5108 & -9.984615 \\
\hline & & & & & \\
\hline & & & & & \\
\hline
\end{tabular}


Table A5: Bootstrap Statistics for Y02

Y02 Estimation

\begin{tabular}{|c|c|c|c|c|c|}
\hline Variables & $\begin{array}{c}\text { Observed } \\
\text { Coef. }\end{array}$ & Bias & $\begin{array}{l}\text { Bootstrap } \\
\text { Std. Err. }\end{array}$ & \multicolumn{2}{|c|}{ Bias Corrected 95\% CI } \\
\hline L.eua_ovs & -0.00004231 & $1.21 \mathrm{e}-07$ & 0.00001489 & -0.0000651 & $-1.14 \mathrm{e}-06$ \\
\hline 1.dummy_ets & 0.30285061 & -0.0872592 & 0.0509891 & 0.3011571 & 0.3669948 \\
\hline empl & 0.00008119 & -0.0000187 & 0.00002739 & 0.0000554 & 0.000174 \\
\hline L.BERD & 0.8967919 & -0.0029875 & 0.18639573 & 0.5580202 & 1.290858 \\
\hline L.GORD & -0.81988383 & 0.8897865 & 0.88158716 & -2.364736 & -0.4961863 \\
\hline L.nace_b & -0.00057921 & -0.0007537 & 0.00231908 & -0.0055886 & 0.0035368 \\
\hline L.nace_c & -0.00587567 & -0.000895 & 0.00374239 & -0.0112374 & 0.0045524 \\
\hline L.nace_d & 0.01520467 & 0.0005891 & 0.0050665 & 0.0042161 & 0.0243689 \\
\hline L.GDP_growth & 0.00099031 & 0.0015025 & 0.01052987 & -0.0238923 & 0.019417 \\
\hline L.renew & 0.00198707 & -0.0034796 & 0.00627198 & -0.0035301 & 0.0334494 \\
\hline _cons & -11.060052 & 0.8044522 & 1.2302487 & -14.42964 & -9.851769 \\
\hline
\end{tabular}


Figure A1: Empirical Distribution of Y02 patent counts, Negative Binomial Distribution, and Poisson Distribution

Fig. A1: Empirical Dist. Y02, Neg. Binom. Dist, and Poisson Dist.

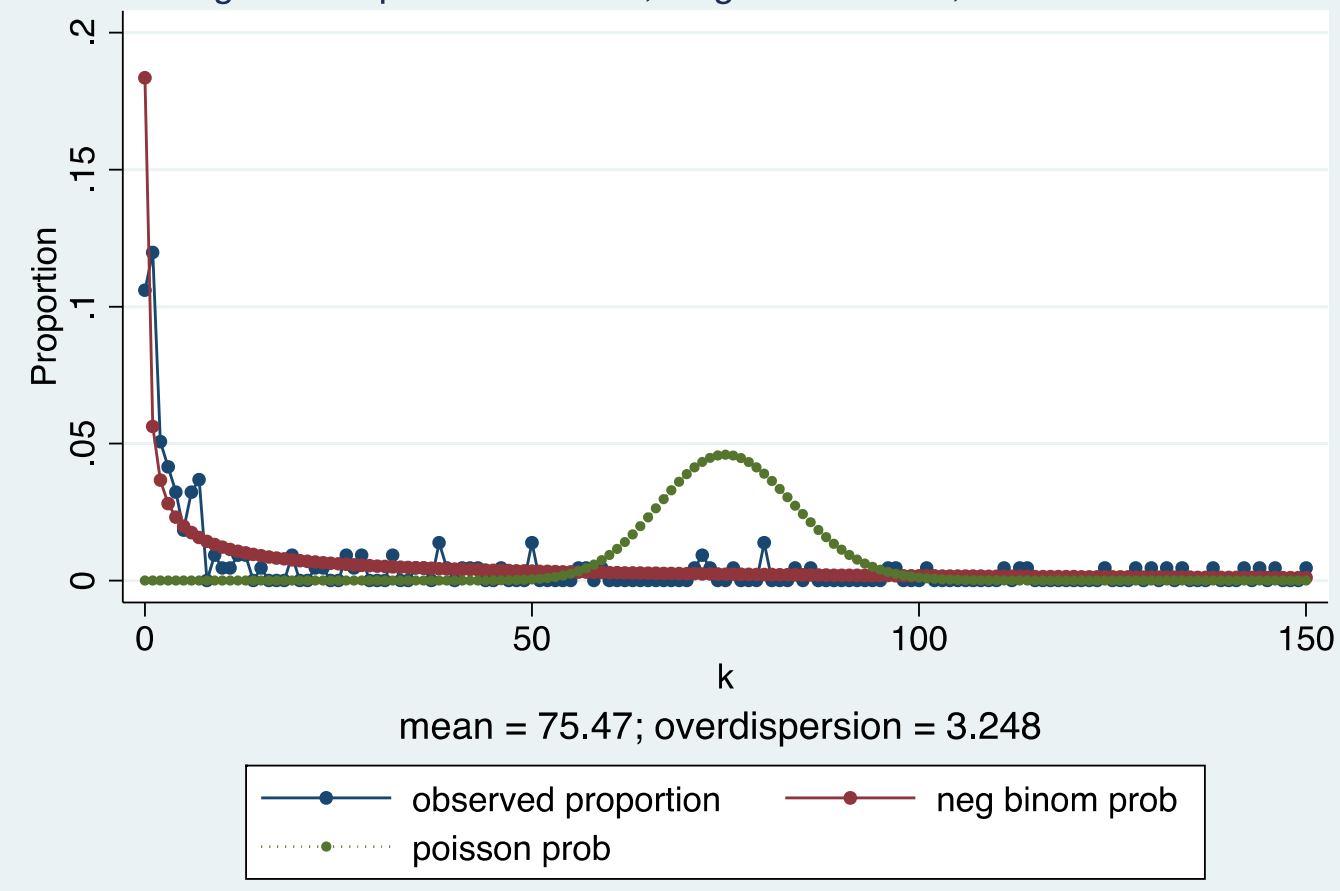

Source: Own Calculation 